\title{
Linking asymmetric division to cell fate: teaching an old microbe new tricks
}

\author{
Richard Losick ${ }^{1}$ and Jonathan Dworkin \\ Department of Molecular and Cellular Biology, The Biological Laboratories, Harvard Univesity, \\ Cambridge, Massachusetts 02138 USA
}

Understanding the connection between cell division and cell fate is a fundamental challenge in developmental biology. In organisms ranging from microbes to mammals, cell division can give rise to progeny cells that differ in fate from one another. In some cases, cell specificity is imposed by external cues that differentially influence the fate of the progeny cells. In other cases, specificity is established by an intrinsic asymmetry in the progenitor cell (Horvitz and Herskowitz 1992). In such cases, cell specificity is frequently attributed to the preferential segregation of a cell-fate determinant to one progeny cell. Thus, in Drosophila melanogaster, the cellfate determinants Numb and Prospero differentially localize to the basal side of the dividing neuroblast, with Prospero doing so in a manner that depends on the localization of another protein (Miranda) to the basal cortex (Hawkins and Garriga 1998). Likewise, in the budding yeast Saccharomyces cerevisiae, the distinct fate of the newborn cell (an inability to undergo a switch in mating type) is determined by the transport into the bud prior to cytokinesis of the mRNA for a repressor protein (ASH1p) that prevents mating type switching (Long et al. 1997; Takizawa et al. 1997). The subject of this review is Bacillus subtilis, a spore-forming bacterium in which a visibly asymmetric process of cell division gives rise to progeny cells that differ in fate from one another as well as from the progenitor cell. Here too, as we shall see, the subcellular distribution of a cell-fate determinant (a serine phosphatase known as SpoIIE) is involved in the establishment of cell fate. As reported in this issue, Frandsen et al. (1999) have, however, cleverly taught B. subtilis the trick of sporulating in a manner that bypasses the SpoIIE determinant. Taking advantage of an idiosyncratic feature of chromosome segregation during asymmetric division, these workers have devised a mechanism of cell specification that is dictated by the asymmetric distribution of a gene, rather than the localization of a protein.

A hallmark of entry into sporulation is the formation of an asymmetrically positioned (polar) septum that divides the developing cell or sporangium into dissimilarsized progeny cells (Piggot and Coote 1976; Stragier and

${ }^{1}$ Corresponding author.

E-MAIL losick@biosun.harvard.edu; FAX (617) 496-4642.
Losick 1996). These are the forespore (the smaller cell) and the mother cell (so named because it will nurse the developing spore). Each progeny cell receives a chromosome from the last round of vegetative DNA replication, but the forespore does so in an unusual manner. In both prokaryotes and eukaryotes, chromosome segregation normally precedes cytokinesis; newly duplicated chromosomes separate from each other and the cell is divided in two by cytokinesis. In sporulation, however, the reverse is true (Wu and Errington 1994, 1998; Wu et al. 1995). The polar septum is formed prior to the incorporation of a complete chromosome into the forespore cell. Instead, only about one-third of the chromosome is present (trapped) in the forespore at the time of polar septation; the remaining two-thirds is translocated across the septum into the forespore after cytokinesis (Fig. 1). This process depends on the SpoIIIE protein, which is located in the septum (Wu and Errington 1997), in which it could form a channel or serve as a DNA translocase or both. Interestingly, the region of the chromosome that is initially trapped in the forespore is not random but rather that portion of the chromosome that is proximal to the origin of replication. This was inferred from the pattern of expression of genes whose transcription is under the control of transcription factor $\sigma^{\mathrm{F}}$, which is active exclusively in the forespore (more about $\sigma^{\mathrm{F}}$ presently): in a spoIIIE mutant only $\sigma^{\mathrm{F}}$-controlled genes located proximal to the origin of replication are expressed (Sun et al. 1991; Wu and Errington 1994, 1998; Wu et al. 1995). Subsequent work demonstrated that early in sporulation the origin regions of the two chromosomes are located near opposite poles of the sporangium so that when asymmetic division takes place only the origin-proximal region is trapped in the forespore (Glaser et al. 1997; Lin et al. 1997; Webb et al. 1997). Indeed, movement of origins toward opposite poles of the cell has emerged as a general feature of chromosome segregation during the vegetative cell cycle of B. subtilis (Glaser et al. 1997; Lin et al. 1997; Webb et al. 1997, 1998), as well as that of other bacteria (Gordon et al. 1997; Mohl and Gober 1997).

Once created by polar division, the mother cell and the forespore follow dissimilar programs of gene expression, which are set in motion by the transcription factors $\sigma^{\mathrm{E}}$ and $\sigma^{\mathrm{F}}$ (for review, see Stragier and Losick 1996). Both 


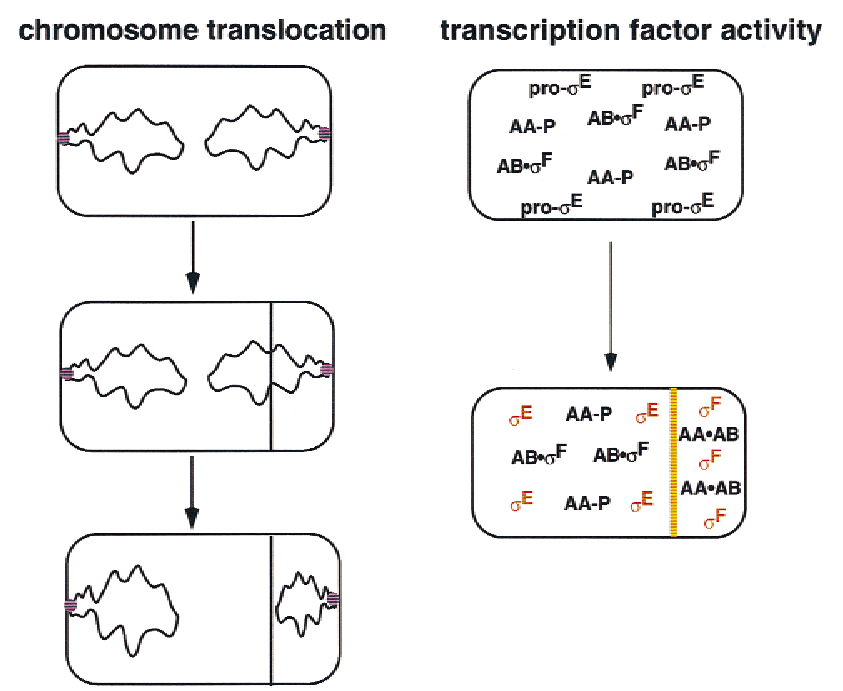

Figure 1. Chromosome segregation and cell-specific activation of $\sigma^{\mathrm{E}}$ and $\sigma^{\mathrm{F}}$. Early in sporulation (top left), the origin regions (purple) of the newly replicated chromosomes are located near opposite poles of the predivisional sporangium. Formation of the polar septum (middle left) initially traps the origin-proximal third of the chromosome in the forespore. Subsequently (bottom left), the remaining two-thirds of the chromosome is translocated into the forespore. Contemporaneously with these events (see the text), the $\sigma^{\mathrm{E}}$ and $\sigma^{\mathrm{F}}$ factors, which are in inactive states in the predivisional sporangium (top right), become active (red) in a cell-specific manner (bottom right). $\mathrm{AB}-\sigma^{\mathrm{F}}, \mathrm{AA}-\mathrm{AB}$, and AA-P refer to SpoIIAB- $\sigma^{\mathrm{F}}$, SpoIIAA-SpoIIAB, and SpoIIAA-P, respectively. The orange bar indicates the septal localization of the SpoIIE phosphatase.

regulatory proteins are produced and present in the predivisional sporangium, but they do not become engaged in directing gene transcription until after asymmetric division when $\sigma^{\mathrm{E}}$ turns on transcription in the mother cell and $\sigma^{\mathrm{F}}$ does so in the forespore (Fig. 1). Why are $\sigma^{\mathrm{E}}$ and $\sigma^{\mathrm{F}}$ inert prior to asymmetric division, and how do they become active in a cell-specific fashion after the formation of the polar septum? Interestingly, the action of the two regulatory proteins becomes compartmentalized by completely unrelated mechanisms. Yet in both cases the polar septum, which can perhaps be thought of as an organelle for the establishment of cell fate, is intimately involved.

Activation of $\sigma^{\mathrm{E}}$ in the mother cell appears to be the composite consequence of two pathways of regulation (Stragier and Losick 1996 and references therein). One pathway operates at the level of the proteolytic processing of an inactive precursor to $\sigma^{\mathrm{E}}$ called pro- $\sigma^{\mathrm{E}}$, which harbors an amino-terminal extension of 27 residues. Pro$\sigma^{\mathrm{E}}$ is present in the predivisional sporangium, where it is associated with the cytoplasmic membrane (Hofmeister 1998). During asymmetric division it comes to localize at the polar septum (Ju et al. 1997; Hofmeister 1998), where it undergoes conversion to mature $\sigma^{\mathrm{E}}$ due to the action of the membrane protein SpoIIGA, which is likely to be the processing enzyme and which is itself located in the polar septum (Fawcett et al. 1998). SpoIIGA is inactive in its default state. For SpoIIGA to bring about the processing of pro- $\sigma^{\mathrm{E}}$, the protease must be activated by a signaling protein called SpoIIR, which is produced in the forespore under the control of $\sigma^{\mathrm{F}}$ (Hofmeister et al. 1995; Karow et al. 1995; Londoño-Vallejo and Stragier 1995; Shazand et al. 1995). SpoIIR is a secreted protein that is believed to interact with SpoIIGA in the intraseptal space between the mother cell and forespore membranes. If so, SpoIIGA can be thought of as a receptor/ protease.

This intercompartmental signaling pathway is a timing device (Driks and Losick 1991; Margolis et al. 1991; Zhang et al. 1996). It delays the processing of pro- $\sigma^{\mathrm{E}}$ until after asymmetric division by tying the activity of the SpoIIGA protease to $\sigma^{\mathrm{F}}$, whose activation, as we shall see, is itself linked to the formation of the polar septum. A separate, and as yet not well understood, pathway is responsible for limiting $\sigma^{\mathrm{E}}$ protein to the mother cell following the formation of the polar septum (Zhang et al. 1996; Pogliano et al. 1997; Ju et al. 1998).

What is the nature of the mechanism that restricts $\sigma^{\mathrm{F}}$ activity to the forespore compartment of the sporangium? The activity of $\sigma^{\mathrm{F}}$ is governed by a three-protein pathway (Stragier and Losick 1996 and references therein) consisting of SpoIIE, a serine phosphatase (Duncan et al. 1995), SpoIIAA, an anti-anti- $\sigma$ factor (Alper et al. 1994; Diederich et al. 1994); and SpoIIAB, a dual-function protein that is both an anti- $\sigma$ factor (Duncan and Losick 1993) and a serine kinase (Min et al. 1993). In brief (and to oversimplify; see Fig. 1), SpoIIAB holds $\sigma^{\mathrm{F}}$ in an inactive complex in the predivisional sporangium and in the mother cell. In the forespore, $\sigma^{\mathrm{F}}$ escapes from the SpoIIAB $-\sigma^{\mathrm{F}}$ complex and is free to associate with core RNA polymerase and direct transcription. This escape occurs by a reaction in which the anti-anti- $\sigma$ factor SpoIIAA attacks the SpoIIAB- $\sigma^{\mathrm{F}}$ complex, causing the release of free $\sigma^{\mathrm{F}}$. SpoIIAA exists in two states: a phosphorylated state (SpoIIAA-P), which is generated by the anti- $\sigma$ factor/kinase SpoIIAB, and an unphosphorylated state (SpoIIAA), which is generated by the action of the serine phosphatase SpoIIE. Only unphosphorylated SpoIIAA is capable of reacting with SpoIIAB- $\sigma^{\mathrm{F}}$ to cause the release of $\sigma^{\mathrm{F}}$. A key and still unsolved aspect of the forespore-specific activation of $\sigma^{\mathrm{F}}$ is the question of how the opposing action of the kinase and phosphatase lead to the preferential accumulation of unphosphorylated SpoIIAA in the forespore.

Evidence suggests that both SpoIIE and SpoIIAB are subject to regulatory inputs that contribute to the cellspecific activation of $\sigma^{\mathrm{F}}$ (Alper et al. 1994; Arigoni et al. 1995, 1999; Levin et al. 1997; Garsin et al. 1998). One of these inputs (the only one we consider here) is the association of SpoIIE, which contains 10 apparent membrane-spanning domains in its amino-terminal region (Arigoni et al. 1999), with the polar septum (Arigoni et al. 1995). Cytokinesis in bacteria is mediated by the tubulin-like protein FtsZ, which polymerizes into a ring (the $\mathrm{Z}$ ring) at the future site of cell division. In sporulating bacteria, the site of Z-ring formation switches from the mid-cell position to sites near both ends of the sporan- 
gium (Levin and Losick 1996). One (and normally only one) of the two polar $\mathrm{Z}$ rings is used for the formation of a septum. SpoIIE colocalizes with the bipolar $\mathrm{Z}$ rings, generating thereby E rings (Levin et al. 1997). During cytokinesis, SpoIIE at the site of asymmetric division invades and becomes part of the polar septum. This is essential for the activation of $\sigma^{\mathrm{F}}$ because in sporangia that have been deprived of FtsZ, SpoIIE fails to localize and $\sigma^{\mathrm{F}}$ is not activated (Levin et al. 1997). This finding is significant because it indicates the existence of an explicit link in the chain of biochemical events from asymmetric division to the activation of $\sigma^{\mathrm{F}}$.

But how does localization of the SpoIIE phosphatase to the polar septum contribute to the compartmentalization of $\sigma^{\mathrm{F}}$ activation? Three models have been considered. In one model SpoIIE is displayed equally on both faces of the polar septum, but because of the extreme asymmetric placement of the septum, the ratio of phosphatase to kinase is higher in the forespore than in the mother cell, thereby favoring the preferential accummulation of unphosphorylated SpoIIAA in the smaller chamber of the sporangium (Arigoni et al. 1995, 1996). A second model is that SpoIIE is on both faces of the septum but active only on the forespore face (Arigoni et al. 1995, 19991, and yet a third model is that SpoIIE is sequestered to the forespore face of the septum (Feucht et al. 1996; Wu et al. 1998). Wu et al. (1998) have argued in favor of the sequestration model on the basis of experiments in which SpoIIE that had been tagged with green fluorescent protein (GFP) was released from the septum by treatment of sporangia with lysozyme. Under such conditions, fluorescence was more intense in the resulting forespore protoplast than in the mother cell protoplast; however, significant fluorescence was still present in the mother cell protoplasts. In any event, whether SpoIIE is more concentrated, selectively active, or sequestered to the forespore, we can think of it as a cellfate determinant that exerts its influence preferentially in one progeny.

It will be clear from the above discussion that although there is much that we still do not understand, the SpoIIE phosphatase and the SpoIIAA anti-anti- $\sigma$ factor play an essential role in the cell-specific activation of $\sigma^{\mathrm{F}}$. It is against this backdrop that the cleverness of the report by Frandsen et al. (1999) should be appreciated for they have created a strain, in fact a series of strains, that entirely lack the gene for SpoIIE or for SpoIIAA and yet are capable of producing spores. They have substituted the asymmetric distribution of the SpoIIE determinant with the asymmetric distribution of the gene for $\sigma^{\mathrm{F}}$ by a strategy that exploits the fact that during sporulation chromosome segregation largely takes place after cytokinesis. As we have seen, following asymmetric division only the origin-proximal one-third of the forespore chromosome is present initially in the forespore. The remainder of the chromosome must be translocated across the septum after cytokinesis. Thus, for a period of several minutes, the origin-proximal portion of the chromosome is present in the forespore and the origin-distal portion is not. Frandsen et al. (1999) capitalized on the transient genetic asymmetry by moving the gene for $\sigma^{\mathrm{F}}$, but not the gene for SpoIIAB, from its normal location to each of thirteen sites at scattered locations around the chromososome. Normally, both genes are located near the terminus of replication (Fig. 2). Not unexpectedly, a strain in which the gene for $\sigma^{\mathrm{F}}$ has been moved to any of these locations sporulates normally. However, when the cells are deprived of SpoIIE or SpoIIAA, those strains, and only those strains, that harbor the $\sigma^{\mathrm{F}}$ gene in the origin-proximal region of the chromosome are capable of sporulating (Fig. 2). Frandsen et al. (1999) suggest that the transient genetic asymmetry of having the gene for $\sigma^{\mathrm{F}}$ present in the forespore in the absence of the gene for its nemesis SpoIIAB results in $\sigma^{\mathrm{F}}$ molecules being synthesized without the corresponding synthesis of the anti- $\sigma$ factor. This leads to a burst of $\sigma^{\mathrm{F}}$ activity exclusively in the forespore that persists at least until the time that the gene for SpoIIAB is finally dragged into the forespore. That is, the asymmetric distribution of a protein (SpoIIE) has been replaced by the asymmetric distribution of a gene.

What is the biological significance of this finding? Obviously, transient genetic asymmetry of the $\sigma^{\mathrm{F}}$ gene is not the normal basis for the compartmentalization of $\sigma^{\mathrm{F}}$

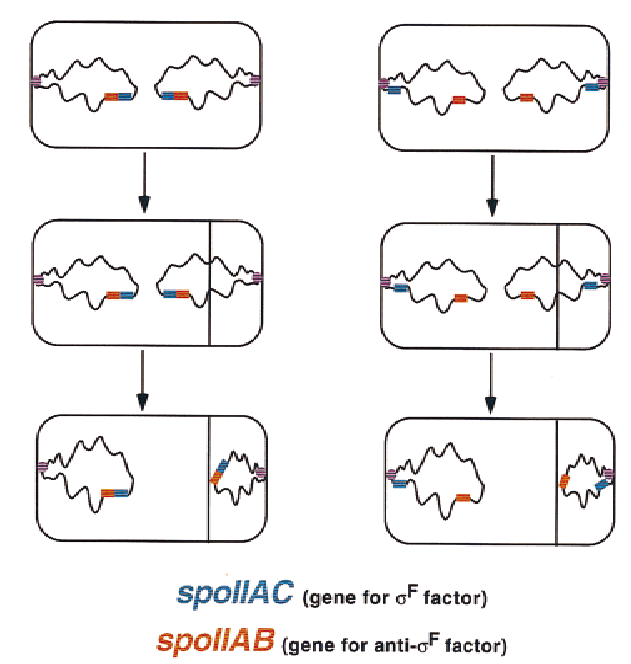

Figure 2. Transient genetic asymmetry of the gene for $\sigma^{\mathrm{F}}$. In wild-type cells (left), the gene for SpoIIAB and and the gene for $\sigma^{\mathrm{F}}$ are located adjacent to each other near the terminus of replication. When the chromosome is bisected by the polar septum, both genes are absent from the forespore until the remainder of the chromosome is translocated into the forespore. In one of the strains constructed by Frandsen et al. (1999) (right), the gene for $\sigma^{\mathrm{F}}$ has been moved to a location near the origin of replication and is therefore present in the forespore in the absence of the gene for SpoIIAB during the period shortly following the formation of the polar septum. In the strain of Frandsen et al., both the forespore and the mother cell are expected to have SpoIIAB- $\sigma^{\mathrm{F}}$ complexes that were synthesized in the predivisional sporangium. In addition, however, the forespore will transiently synthesize additional $\sigma^{\mathrm{F}}$ molecules without the corresponding synthesis of SpoIIAB molecules. This allows such a strain to sporulate even in the absence of the SpoIIE phosphatase or the SpoIIAA anti-anti- $\sigma$ factor. 
activity. But perhaps, as Frandsen et al. (1999) speculate, the gene for a hypothetical inhibitor of the SpoIIE phosphatase is located in the origin-distal region of the chromosome. If so, for a period of time two copies of the gene would be present in the mother cell and none in the forespore. It will be of much interest to learn whether $B$. subtilis has been clever enough to exploit transient genetic asymmetry on its own. Have Frandsen et al. taught this old microbe a new trick or one that it knew all along?

\section{Acknowledgments}

J.D. is supported by National Research Service Award fellowship 1F32-GM19729. Work in the laboratory of R.L. is supported by National Institutes of Health grant GM18568.

\section{References}

Alper, S., L. Duncan, and R. Losick. 1994. An adenosine nucleotide switch controlling the activity of a cell type-specific transcription factor in B. subtilis. Cell 77: 195-205.

Arigoni, F., K. Pogliano, C.D. Webb, P. Stragier, and R. Losick. 1995. Localization of protein implicated in establishment of cell type to sites of asymmetric division. Science 270: 637640.

Arigoni, F., L. Duncan, S. Alper, R. Losick, and P. Stragier. 1996. SpoIIE governs the phosphorylation state of a protein regulating transcription factor sigma $\mathrm{F}$ during sporulation in $\mathrm{Ba}$ cillus subtilis. Proc. Nat1. Acad. Sci. 93: 3238-3242.

Arigoni, F., A.-M. Guérout-Fleury, I. Barák, and P. Stragier. 1999. The SpoIIE phosphatase, the sporulation septum, and the establishment of forespore-specific transcription in $\mathrm{Ba}$ cillus subtilis: a reassessment. Mol. Microbiol. (in press).

Diederich, B., J.F. Wilkinson, T. Magnin, M. Najafi, J. Erringston, and M.D. Yudkin. 1994. Role of interactions between SpoIIAA and SpoIIAB in regulating cell-specific transcription factor $\sigma^{\mathrm{F}}$ of Bacillus subtilis. Genes \& Dev. 8: 2653-2663.

Driks, A. and R. Losick. 1991. Compartmentalized expression of a gene under the control of sporulation transcription factor $\sigma^{\mathrm{E}}$ in Bacillus subtilis. Proc. Nat1. Acad. Sci. 88: 9934-9938.

Duncan, L. and R. Losick. 1993. SpoIIAB is an anti- $\sigma$ factor that binds to and inhibits transcription by regulatory protein $\sigma^{\mathrm{F}}$ from Bacillus subtilis. Proc. Natl. Acad. Sci. 90: 2325-2329.

Duncan, L., S. Alper, F. Arigoni, R. Losick, and P. Stragier. 1995. Activation of a cell-specific transcription factor by a serine phosphatase at the site of asymmetric division. Science 270: 641-644.

Fawcett, P., A. Melnikov, and P. Youngman. 1998. The Bacillus SpoIIGA protein is targeted to sites of spore septum formation in a SpoIIE-independent manner. Mol. Microbiol. 28: 931-933.

Feucht, A., T. Magnin, M.D. Yudkin, and J. Errington. 1996. Bifunctional protein required for asymmetric cell division and cell-specific transcription in Bacillus subtilis. Genes \& Dev. 10: 794-803.

Frandsen, N., I. Bárak, and P. Stragier. 1999. Transient gene asymmetry during sporulation and establishment of cell specificity in Bacillus subtilis. Genes \& Dev. (this issue).

Garsin, D.A., L. Duncan, D.M. Paskowitz, and R. Losick. 1998. The kinase activity of the antisigma factor SpoIIAB is required for activation as well as inhibition of transcription factor $\sigma^{\mathrm{F}}$ during sporulation in Bacillus subtilis. J. Mol. Biol.
284: 569-578.

Glaser, P., M.E. Sharpe, B. Raether, M. Perego, K. Ohlsen, and J. Errington. 1997. Dynamic, mitotic-like behavior of a bacterial protein required for accurate chromosome partitioning. Genes \& Dev. 11: 1160-1168.

Gordon, G.S., D. Sitnikov, C.D. Webb, A. Teleman, A. Straight, R. Losick, A.W. Murray, and A. Wright. 1997. Chromosome and low copy plasmid segregation in E. coli: Visual evidence for distinct mechanisms. Cell 90: 1-20.

Hawkins, N. and G. Garriga. 1998. Asymmetric cell division: From A to Z. Genes \& Dev. 12: 3625-3638.

Hofmeister, A. 1998. Activation of the proprotein transcription factor pro- $\sigma^{\mathrm{E}}$ is associated with its progression through three patterns of subcellular localization during sporulation in $\mathrm{Ba}$ cillus subtilis. J. Bacteriol. 180: 2426-2433.

Hofmeister, A.E.M., A. Londoño-Vallejo, E. Harry, P. Stragier, and R. Losick. 1995. Extracellular signal protein triggering the proteolytic activation of a developmental transcription factor in Bacillus subtilis. Cell 83: 219-226.

Horvitz, R. and I. Herskowitz. 1992. Mechanisms of asymmetric cell division: Two Bs or not two Bs, that is the question. Cell 68: 237-255.

Ju, J., T. Luo, and W.G. Haldenwang. 1997. Bacillus subtilis Pro- $\sigma^{\mathrm{E}}$ fusion protein localizes to the forespore septum and fails to be processed when synthesized in the forespore. $J$. Bacteriol. 179: 4888-4893.

- 1998. Forespore expression and processing of the SigE transcription factor in wild-type and mutant Bacillus subtilis. J. Bacteriol. 180: 1673-1681.

Karow, L.M., P. Glaser, and P.J. Piggot. 1995. Identification of a gene, spoIIR, which links the activation of $\sigma^{\mathrm{E}}$ to the transcriptional activity of $\sigma^{\mathrm{F}}$ during sporulation in Bacillus subtilis. Proc. Natl. Acad. Sci. 92: 2012-2016.

Levin, P.A. and R. Losick. 1996. Transcription factor Spo0A switches the localization of the cell division protein FtsZ from a medial to a bipolar pattern in Bacillus subtilis. Genes \& Dev. 10: 478-488.

Levin, P.A., R. Losick, P. Stragier, and F. Arigoni. 1997. Localization of the sporulation protein SpoIIE in Bacillus subtilis is dependent upon the cell division protein FtsZ. Mol. Microbiol. 25: 839-846.

Lin, D.C.H., P.A. Levin, and A.D. Grossman. 1997. Bipolar localization of a chromosome partition protein in Bacillus subtilis. Proc. Natl. Acad. Sci. 94: 4721-4726.

Londoño-Vallejo, J.A. and P. Stragier. 1995. Cell-cell signaling pathway activating a developmental transcription factor in Bacillus subtilis. Genes \& Dev. 9: 503-508.

Long, R.M., R.H. Singer, X. Meng, I. Gonzalez, K. Nasmyth, and R.P. Jansen. 1997. Mating type switching in yeast controlled by asymmetric localization of ASH1 mRNA. Science 277: 383-387.

Margolis, P., A. Driks, and R. Losick. 1991. Establishment of cell type by compartmentalized activation of a transcription factor. Science 254: 562-565.

Min, K.-T., C.M. Hilditch, B. Diederich, J. Errington, and M.D. Yudkin. 1993. $\sigma^{\mathrm{F}}$, the first compartment-specific transcription factor of Bacillus subtilis, is regulated by an anti- $\sigma$ factor that is also a protein kinase. Cell 74: 735-742.

Mohl, D.A. and J.W. Gober. 1997. Cell cycle-dependent polar localization of chromosome partitioning proteins in Caulobacter crescentus. Cell 88: 675-684.

Piggot, P.J. and J.G. Coote. 1976. Genetic aspects of bacterial endospore formation. Bacteriol. Rev. 40: 908-962.

Pogliano, K., A.E.M. Hofmeister, and R. Losick. 1997. Disappearance of the $\sigma^{\mathrm{E}}$ transcription factor from the forespore and the SpoIIE phosphatase from the mother cell contributes 
to the establishment of cell-specific gene expression during sporulation in Bacillus subtilis. J. Bacteriol. 179: 3331-3341.

Shazand, K., N. Frandsen, and P. Stragier. 1995. Cell-type specificity during development in Bacillus subtilis: The molecular and morphological requirements for $\sigma^{\mathrm{E}}$ activation. $E M B O$ J. 14: 1439-1445.

Stragier, P. and R. Losick. 1996. Molecular genetics of sporulation in Bacillus subtilis. Annu. Rev. Genet. 30: 297-341.

Sun, D., P. Fajardo-Cavazos, M.D. Sussman, F. Tovar-Rojo, R.-M. Cabrera-Martinez, and P. Setlow. 1991. Effect of chromosome location of Bacillus subtilis forespore genes on their spo gene dependence and transcription by $\mathrm{E}^{\mathrm{F}}$ : Identification of features of good $\mathrm{E}^{\mathrm{F}}$-dependent promoters. J. Bacteriol. 173: 7867-7874.

Takizawa, P.A., A. Sil, J.R. Swedlow, I. Herskowitz, and R.D. Vale. 1997. Actin-dependent localization of an RNA encoding a cell-fate determinant in yeast. Nature 389: 90-93.

Webb, C.D., A. Teleman, S. Gordon, A. Straight, A. Belmont, D.C. Lin, A.D. Grossman, A. Wright, and R. Losick. 1997. Bipolar localization of the replication origin regions of chromosomes in vegetative and sporulating cells of $B$. subtilis. Cell 88: 667-674.

Webb, C.D., P.L. Graumann, J.A. Kahana, A.A. Teleman, P.A. Silver, and R. Losick. 1998. Use of time-lapse microscopy to visualize rapid movement of the replication origin region of the chromosome during the cell cycle in Bacillus subtilis Mol. Microbiol. 28: 883-892.

Wu, L. and J. Errington. 1994. Bacillus subtilis SpoIIIE protein required for DNA segregation during asymmetric cell division. Science 264: 572-575.

- 1997. Septal localization of the SpoIIIE chromosome partitioning protein in Bacillus subtilis. EMBO J. 16: 21612169.

1998. Use of asymmetric cell division and spoIIIE mutants to probe chromosome orientation and organization in Bacillus subtilis. Mol. Microbiol. 27: 777-786.

Wu, L.J., P.J. Lewis, R. Allmansberger, P.M. Hauser, and J. Errington. 1995. A conjugation-like mechanism for prespore chromosome partitioning during sporulation in Bacillus subtilis. Genes \& Dev. 9: 1316-1326.

Wu, L.J., A. Feucht, and J. Errington. 1998. Prespore-specific gene expression in Bacillus subtilis is driven by sequestration of SpoIIE phosphatase to the prespore side of the asymmetric septum. Genes \& Dev. 12: 1371-1380.

Zhang, L., M.L. Higgins, P.J. Piggot, and M.L. Karow. 1996. Analysis of the role of prespore gene expression in the compartmentalization of mother cell-specific gene expression during sporulation of Bacillus subtilis. J. Bacteriol. 178: 813-2817. 


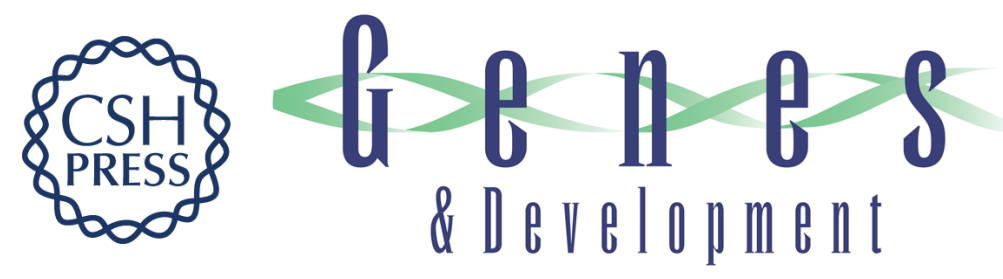

\section{Linking asymmetric division to cell fate: teaching an old microbe new tricks}

Richard Losick and Jonathan Dworkin

Genes Dev. 1999, 13:

\section{References This article cites 40 articles, 25 of which can be accessed free at: http://genesdev.cshlp.org/content/13/4/377.full.html\#ref-list-1 \\ License}
Email Alerting Receive free email alerts when new articles cite this article - sign up in the box at the top Service right corner of the article or click here.

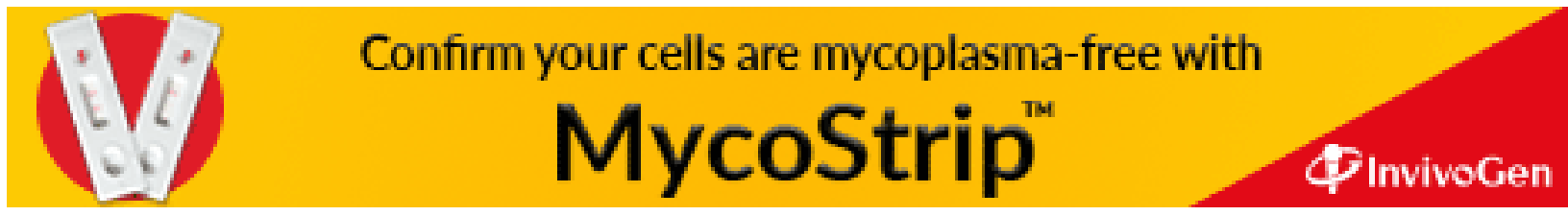

